\title{
ESTRANGEIRO, NUNCA MAIS! MIGRANTE COMO SUJEITO DE DIREITO E A IMPORTÂNCIA DO ADVOCACY PELA NOVA LEI DE MIGRAÇÃO BRASILEIRA
}

Foreigner, never again! Migrant as a subject of rights and the importance of Advocacy under the New Brazilian Migration Law

\author{
OLIVEIRA, Ebenézer Marcelo Marques de; SAMPAIO, Cyntia. \\ São Paulo: Centro de Estudos Migratórios, 2020. 259p.
}

Andrea Pacheco Pacifico* Sarah Fernanda Lemos Silva*

"Estrangeiro, nunca mais! Migrante como sujeito de direito e a importância do Advocacy pela Nova Lei de Migração Brasileira" é um livro importante como ferramenta para a prática de advocacy no Brasil e, quicá, alhures. Fruto de pesquisa concisa de Ebenézer Marcelo M. de Oliveira, mestre em Políticas Públicas (UFABC), e Cyntia Sampaio, consultora independente que atuou no sistema ONU por dez anos, a obra guia o leitor pelo período de tramitação da Nova Lei de Refúgio (13.445/2017), pontuando estratégias de advocacy utilizadas pela sociedade civil durante sua criação.

Versando sobre uma lei em vigor, o livro traz análises essenciais, recriando o passo-a-passo de sua tramitação e do processo de atuação da sociedade civil em torno dela, apontando erros e acertos e entrevistas com membros da sociedade civil que participaram deste fundamental processo para consolidá-la. Sendo acadêmico, faz breve revisão de literatura, familiarizando leitores com o tema para que compreendam conceitos e, ainda, reúne, em uma só obra, tudo o que um pesquisador precisa saber sobre o processo de advocacy na nova lei.

Dividido em quatro capítulos, o primeiro, "A nova lei de migração brasileira e o contexto brasileiro das migrações", descreve, historicamente, as migrações para o Brasil, mostrando como o processo migratório no país culminou

\footnotetext{
Professora do Curso de Graduação e do Programa de Pós-Graduação em Relações Internacionais (RI) da Universidade Estadual da Paraíba. João Pessoa, PB, Brasil. E-mail: apacifico@hotmail.com. Orcid: https://orcid.org/0000-0002-2744-7166.

** Mestranda no Programa de Pós-Graduação em Relações Internacionais (RI), Universidade Estadual da Paraíba. João Pessoa, PB, Brasil. E-mail: sarah.f.lemos@hotmail.com. Orcid: http:// orcid.org/0000-0002-6929-6597.
} 
em políticas migratórias restritivas (p. 19). A análise histórica, teoricamente fundamentada, compreende contextos histórico-legislativos, marcos políticos, atuações institucionais e diferentes fluxos migratórios recebidos, incluindo-se conceitos, como transmigração, ou seja, vínculos de natureza diversa entre o lugar de origem ou referência e o de estabelecimento ou chegada (Solé, Parella, Cavalcanti, 2008, p. 14).

O segundo capítulo, "Abordagem teórica sobre advocacy", diferencia o conceito de lobby de advocacy, sendo o primeiro acometido de conotação negativa e o segundo com base em Brelàz (2007), para quem o termo se refere à promoção de uma causa. Aqui, os autores analisam desafios e estratégias para fazer advocacy.

O terceiro capítulo, "Tramitação, advocacy e resultados da nova lei de migração", reconstrói minuciosamente o processo de tramitação da lei, destacando a atuação da sociedade civil e o papel da Comissão de Relações Exteriores e Defesa Nacional (Senado), que, segundo os autores, foi onde o governo atuou em conjunto com a sociedade civil na tentativa de modificar a primeira proposta do atual texto da lei (p. 129). Outro ponto de destaque foi a "Carta Aberta de apoio à mudança da lei atual sobre migração", apresentada, em 2014, ao governo, por 40 entidades da sociedade civil, com cinco princípios norteadores para a lei, quais sejam: garantia dos direitos humanos; procedimentos de regularização migratória rápidos, efetivos e acessíveis; não criminalização; controle judicial e acesso à justiça; e criação de uma instituição nacional autônoma para aplicar a lei. Os autores destacaram, também, a presença da população durante as votações, com cartazes e nas redes socais, em apoio aos deputados aliados à causa durante a votação do Projeto de Lei.

O capítulo ainda analisou momentos-chave do advocacy sobre o tema, como a Comigrar e o Fórum Social Mundial das Migrações; este último com parlamentares envolvidos nos projetos da nova lei (p. 146). Analisando os êxitos da nova lei, os autores selecionaram: aspectos legais, destacando-se o distanciamento de aparatos e interpretações que a lei apresentou do Estatuto do Estrangeiro e da Política Nacional de Migração; aspectos simbólicos, destacando-se a quebra que vinha desde o Estatuto do Estrangeiro em tratar a migração sob olhos da segurança nacional, reconhecendo, agora, o migrante como sujeito de direitos ( $p$. 148); aspectos operacionais, destacando-se a garantia do devido processo legal; e, por fim, aspectos individuais, destacando-se a melhoria das condições de vida dos migrantes, pelos princípios da não criminalização e da acolhida humanitária, e alterações nos trâmites do pedido de residência, que permitiram ao migrante não precisar mais deixar o país para fazê-lo. De fato, apesar de vetos presidenciais à lei, o estrangeiro no Brasil deixa de ser visto, na nova lei, como ameaça à segurança nacional (rótulo do antigo Estatuto do Estrangeiro, Lei 6815/1980) e passa a ser sujeito de direito, ou seja, parte de uma relação de direito, deveres e obrigações entre ele e o estado acolhedor, incluindo-se à criação do visto 
humanitário, como visto em Moreira (2017, p. 28) e em Pacífico e Ramos (2015, p. 218-239).

O quarto capítulo apresenta alguns principais erros e acertos no trajeto da advocacy pela nova lei. "Desafios, estratégias e lições aprendidas sobre advocacy da nova lei de migração" é capítulo fundamental, particularmente devido à sua originalidade. Quanto aos desafios enfrentados pela advocacy, os autores apontam a luta constante, na prática, de grupos no processo legislativo, além de xenofobia, rivalidade histórica de organizações da sociedade civil, falta de recursos financeiros para sustentar a prática, organizações que buscam uma maior visibilidade, necessidade de atuação em coalizão etc. Mister destacar que a análise destes desafios foi realizada unindo teorias aplicadas à prática.

O mesmo capítulo mostra ainda o protagonismo da sociedade civil no processo da advocacy, listando importantes estratégias utilizadas, o trabalho técnico realizado, a gradual atuação política de algumas organizações, a formação de uma rede de indivíduos e organizações e a pressão social exercida. Outro destaque, que enseja importantes questionamentos, foi a análise da participação e da representação direta de migrantes no processo, apontada como tímida e entendida como uma falha no processo (p. 186).

Finalizando o capítulo, foram apresentadas lições aprendidas com a advocacy da nova lei de migração: necessidade de planejamento prévio, mas entendendo que nem sempre é possível prever tudo; importância de conhecimentos técnicos e acadêmicos para auxiliar a construir o texto da lei; conhecimento prático das organizações envolvidas; utilização de canais de diálogo já existentes; pressão popular, que deve ser utilizada em momentos certos para não atrapalhar negociações; atuação em todas as fases da tramitação; e conhecimento e mapeamento de parlamentares envolvidos.

Saliente-se que, embora os capítulos 1 e 2, cerca de metade do livro, sejam bastante descritivos, com citações muito longas, a originalidade e a importância da pesquisa reforçam o papel crucial, particularmente na advocacy, do migrante, como sujeito de direito, no apoio à sociedade civil para aprovar a atual Lei de Migração brasileira.

Diferentemente do simples ativismo, a advocacy, como um constructo, é mais genérica e mais abrangente, podendo incluir diversas ações, públicas ou privadas, com diferentes graus de conflitos entre as partes. Essa advocacy, analisada no processo de elaboração e aprovação da Lei brasileira em epígrafe, pode ser um exemplo para migrantes dos mais diversos rincões do mundo, que já realizam ativismo, com apoio ou não da sociedade civil local.

Trata-se, portanto, de um livro essencial para pesquisadores e praticantes da área das migrações, por unir interpretações teóricas a entrevistas e práticas que podem e devem ser aplicadas em outros momentos de luta para conquista de direitos dos migrantes no Brasil e alhures. 


\section{Referências bibliográficas}

BRELÀZ, Gabriela de. Advocacy das organizações da sociedade civil: um estudo comparativo entre Brasil e Estados Unidos. Dissertação de Mestrado. Rio de Janeiro: Escola de Administração de Empresas de São Paulo da Fundação Getúlio Vargas, 2007.

MOREIRA, Julia Bertino. Refugee Policy in Brazil (1995-2010): Achievements and Challenges. Refugee Survey Quarterly, v. 36, p. 25-44, 2017.

PACIFICO, Andrea Pacheco; RAMOS, Érika Pires. Humanitarian Asylum for Forced Migrants: the case of Haitians' arrival in Brazil. In: GAUCl, Jean-Pierre; GIUFFRÉ, Mariagiulia; TSOURDI, Evangelia (eds.). Exploring the Boundaries of Refugee Law: Current Protection Challenges. International Refugee Law Series, v. 3, Leiden/Boston: Brill/Nijhoff, 2015, p. 218-239.

SOLÉ, Carlota; PARELLA, Sónia; CAVALCANTI, Leonardo (coord.). Nuevos retos del transnacionalismo en el estudio de las migraciones. Documentos del Observatorio Permanente de la inmigración n. 19. Madrid: MTI, 2008, p. 11-20. 